\section{in a returned traveller}

A previously healthy 26 -year-old man presented for evaluation of a non-healing nodule on the medial aspect of his right heel. The lesion began while he was on holiday in Peru 4 weeks previously. He did not recall any bite or trauma. He had worn shoes most of the time, but he had spent some time on beaches and had not worn footwear while sleeping. The lesion began as a $1-\mathrm{mm}$ pruritic and painless black spot with surrounding redness and resulted in discomfort when walking. The patient reported minor serosanguinous discharge and increasing erythema. There were no systemic symptoms.

On examination, the patient looked well and was afebrile. The nodule on his right heel was $1 \mathrm{~cm}$ in diameter, with hyperkeratosis surrounding a 3mm black centre with surrounding erythema. The nodule was nontender and exuded a serous discharge. There were no other cutaneous or mucocutaneous findings or lymphadenopathy.

The lesion was deroofed (Fig. I) and its contents of eggs and feces expressed and transported in formalin
CLINICAL Vistas

\section{A non-healing nodule}

(Fig. 2). Examination of the nodule base revealed a 6 -mm dark brown spherical foreign body that was firmly attached to the base and was macerated during removal. A clinical diagnosis of tungiasis was made. The lesion was washed daily with 10\% povidone iodine, and a course of cephalexin was given for the cellulitis. Culture of the ulcer base subsequently grew Staphylococcus aureus and a group $\mathrm{G}$ streptococcus. The patient had received tetanus toxoid immunization in the past 5 years. Within a week the erythema had resolved and the lesion was healing well.

Tungiasis is an uncommon ectoparasitic infection caused by the sand flea Tunga penetrans. Originally endemic to South America, it is now also found in Central America, the Caribbean, Asia and Africa. The flea's habitat is moist, sandy areas. The prevalence of tungiasis among local inhabitants of some regions reaches $50 \% .{ }^{1}$ However, North American travellers are rarely affected.

The flea has limited jumping ability, and infestation typically occurs on the feet. The fertilized female burrows into the skin, its head toward the epidermal-dermal junction and its analgenital opening near the surface,

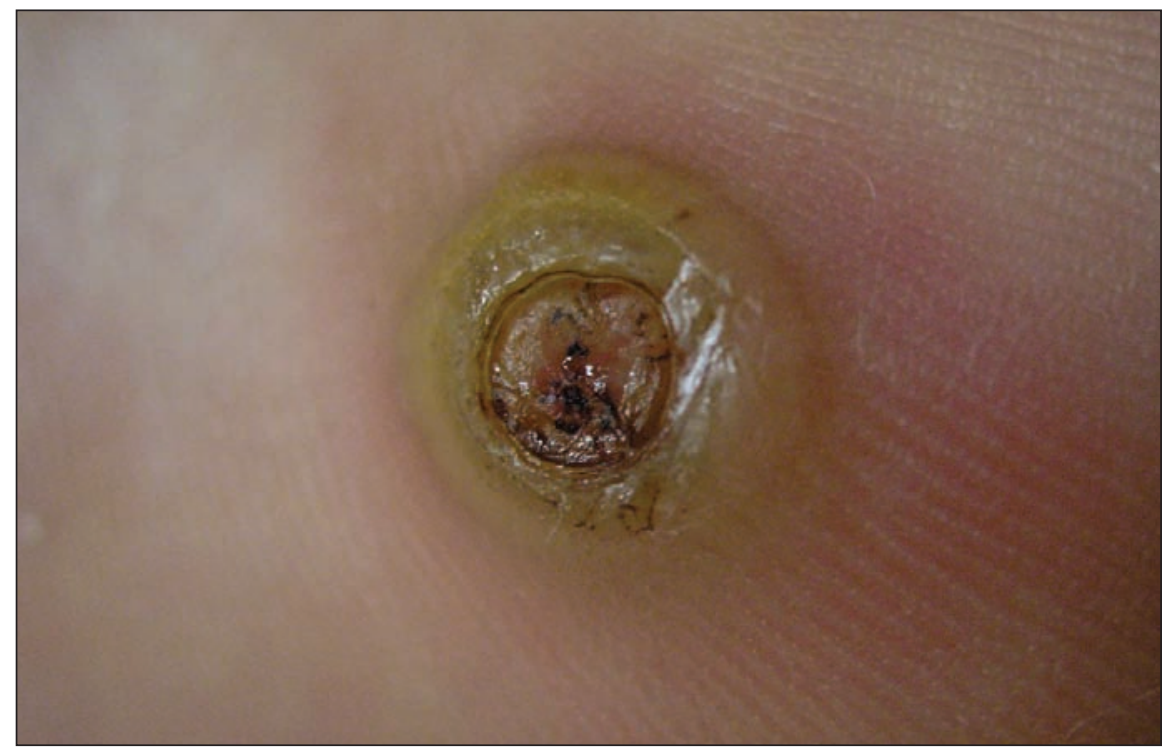

Fig 1: Deroofed nodule, $1 \mathrm{~cm}$ in diameter, on the heel of a man who had travelled to a tungiasis-endemic area.

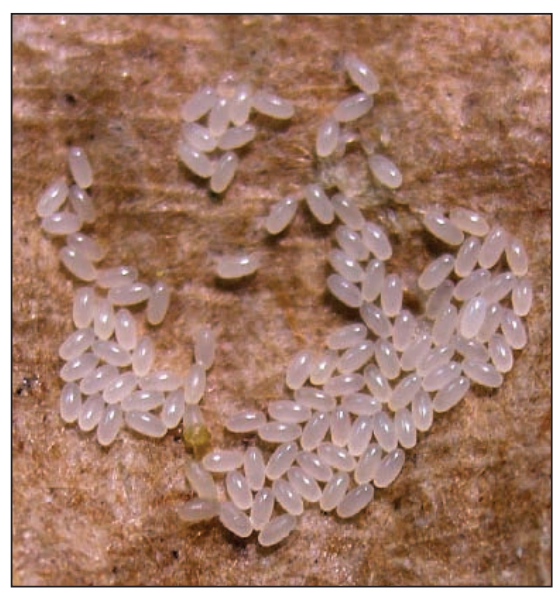

Fig 2: Eggs and feces of the sand flea Tunga penetrans removed from the nodule.

which produces a pruritic reddish spot. The flea feeds on blood and enlarges to the size of a pea, which results in a whitish nodule with a central black dot corresponding to the anal-genital opening. One to 3 weeks after penetration, the flea expels eggs from the central opening. About 5 weeks after penetration, the flea dies and is sloughed off, leaving an ulcer that heals slowly. ${ }^{1,2}$

Diagnosis is suggested by the history and confirmed by discovery of the parasite and eggs within the lesion. ${ }^{1,2}$ The differential diagnosis in the traveller includes leishmaniasis, myiasis, dracunculiasis and cutaneous larva migrans as well as non-travel-related infections. $^{3}$

Although the infestation is selflimited, tungiasis can result in disfigurement, superinfection, bacteremia, gas gangrene and tetanus. ${ }^{2,3}$ Management consists of removal of the nodule contents and leaving the remaining ulcer to heal, or surgical excision of the whole lesion. ${ }^{2,3}$ After extraction, the crater should be thoroughly cleaned and an antiseptic applied. Pending wound culture results, empiric antimicrobial therapy should be given if there are signs of superinfection. Tetanus prophylaxis is indicated. $^{3}$ Antiparasitic agents have had limited success and are not indicated in travellers with few lesions. ${ }^{2}$ The use of insecticides on infested soils and domestic animals reduces the flea bur- 
den. Prevention consists of wearing closed footwear while visiting tungiasis-endemic areas. In addition, a biological repellent made from coconut and jojoba oil appears to be effective in reducing infestations. ${ }^{3}$

\section{Philippe R.S. Lagacé-Wiens}

Godfrey K.M. Harding

Department of Medical Microbiology

and Infectious Diseases

Faculty of Medicine

University of Manitoba

Winnipeg, Man.

Competing interests: None declared.

Acknowledgement: We thank Dr. Michelle Alfa for her help in the laboratory diagnosis of the tungiasis.

\section{REFERENCES}

I. Feldmeier H, Eisele M, Van Marck E, et al. Investigations on the biology, epidemiology, pathology and control of Tunga penetrans in Brazil: IV. Clinical and histopathology. Parasitol Res 2004;94(4):275-82.

2. Marrero MD, Nagore E, Igual-Adell R, et al. Tungiasis presenting with whitish nodules on the feet. $J$ Eur Acad Dermatol Venereol Mar 2003;17(2):247-8.

3. Heukelbach J. Tungiasis. Orphanet Encyclopedia Sept 2004. Available: www.orpha.net/data/patho /GB/uk-Tungiasis.pdf (accessed 2005 Oct I8).

\section{BOOKS RECEIVED}

Cook RJ, Dickens BM, Fathalla MF. Santé de la reproduction et droits humains: intégrer la médecine, l'éthique et le droit. Paris: Masson; 2005. 544 pp. \$35 ISBN 2-294-02I64-9

Cullen R. Health information on the internet: a study of providers, qualilty, and users. Westport (CT): Greenwood Publishing Group; 2006. 256 pp. \$29.95 ISBN 0-86569-322-6

Evans M, editor. Mosby's family practice sourcebook: an evidence-based approach to care, $4^{\text {th }}$ ed. Toronto: Elsevier Canada; 2005. 608 pp. \$IIo ISBN 0-7796-9906-8

Fekrat S, Weiser JS, editors. All about your eyes. North Carolina: Duke University Press; 2006. 179 pp. \$18.95 ISBN o8223-3699-5

Glover, RV. Journey to wellness: designing a people-centred health system for Canadians. Toronto: Hushion House Publishing Limited; 2005. I83 pp. \$19.95 ISNB 0-9733212-7-X
Hays, R. Teaching and learning in primary care. Oxon (UK): Radcliffe Publishing Limited; 2005. I44 pp. \$2I.95 ISBN I- $85775-756-4$

Johnson ML, editor. The Cambridge handbook of age and ageing. Cambridge (UK): Cambridge University Press; 2005 . 743 pp. \$IIO ISBN 0-52I-82632-2

Lee-Chiong TL. Sleep: a comprehensive handbook. New Jersey: John Wiley \& Sons, Inc.; 2005. I058 pp. ISBN 0-47I6837I-X

Miner JT, Miner LE. Directory of biomedical and health care grants 2006, 26th ed. Westport: Oryx Press; 2006. 650 pp. ISBN I-57356-6r8-7

Rees J, Kanabar D. ABC of asthma, $5^{\text {th }}$ ed. Oxford (UK): Blackwell Publishing; 2005. 63 pp. \$34.95 ISBN 0-7279-I86o-5

World Health Organization. Pocket book of hospital care for children: guidelines for the management of common illnesses with limited resources. Switzerland: World Health Organization; 2005. 366 pp. \$I8 ISBN 92-4-I54670-0

\section{Statistics Canada Presents:}

Perspectives on Canada

Health, Well-Being \& Quality of Life

April 6, 2006, Toronto

A conference designed to stimulate ideas and new approaches on these themes in the public and private marketplace.

\section{Keynote speakers:}

Dr. Sheela Basrur, Ontario's Chief Medical Officer of Health and Assistant Deputy Minister

Dr. Douglas Norris, former Director General, Statistics Canada

Become engaged in presentations and dynamic panel discussions with public and private sector representatives.

For more information:

www.statcan.ca/perspectives2006

\section{Statistique Canada présente: \\ Perspectives sur le Canada \\ Santé, bien-être et qualité de vie} Le 6 avril à Toronto

Une conférence conçue pour susciter des idées de nouvelles approches liées à ces thèmes pour les marchés public et privé.

Conférenciers principaux:

$D^{\text {re }}$ Sheela Basrur, médecin hygiéniste en chef et sous-ministre adjointe

M. Douglas Norris, Ph.D., ancien directeur général de Statistique Canada

De plus, participez à des discussions animées regroupant des représentants du secteur public et du secteur privé.

Pour de plus amples renseignements: www.statcan.ca/perspectives2006fr 